\title{
SAN AGUSTÍN: PERENNE CANDIL QUE ILUMINA A LA IGLESIA
}

\author{
Pablo Antonio Morillo Rey \\ Centro de Estudios Teológicos-Sevilla
}

\section{RESUMEN / ABSTRACT}

A lo largo de la historia de la Iglesia, podemos comprobar cómo el magisterio agustiniano se convirtió en una constante, que perdura hasta nuestros días. Así, San Agustín ha sido (es y será) una "inagotable fuente" de inspiración tanto para Pontífices como para numerosos documentos eclesiales. De esta forma, en el presente artículo analizamos- entre otros aspectos- tanto la encíclica Lumen Fidei (29 Junio de 2013) como la Nueva edición del Directorio para la vida y ministerio de los presbiteros (11 Febrero de 2013), ambos documentos influenciados e ilustrados con el magisterio del Santo Obispo de Hipona, magisterio que- como bien señaló el beato Juan Pablo II en su encíclica Augustinum Hipponensemdebe continuar "en la Iglesia y en el mundo a beneficio de la cultura $y$ de la fe" (Conclusión).

Thorough the Church history, the Augustinian magister was a constant, staying nowadays. Therefore, St. Agustin has been, is and will be an unstopped source of inspiration for Popes and Church documents. We study both Lumen Fidei (June 29, 2013 and the New Edition of the Directory for presbyters' life and ministry (February, $11^{\text {th }}$, 2013, which are inspired on the Hipona Saint Bishop's Magister. A magister that should keep serving to the Church and the World, being beneficial for culture and faith, as it was said by Beatus Pope John Paul II in his Encyclical Augustinium Hipponensem. 
“...dar nuestras más sinceras gracias a nuestro Padre Celestial por haber enriquecido su Iglesia con tan grandes y numerosos beneficios a través de Agustin"

(Pio XI, "Ad salutem humani generis")

\section{INTRODUCCIÓN}

"Siempre que el pensamiento cristiano se aleja de San Agustin se debilita y languidece; siempre que vuelve a él se enciende con nueva llama y brio"1.

Estas palabras de Maurice Blondel (1861-1949) constituyen un claro ejemplo de la rica e inmensa aportación que el magisterio agustiniano aporta al pensamiento cristiano. Por otro lado, igualmente se podria atisbar en dichas palabras como una especie de "advertencia" para todo el orbe cristiano católico, pues- sin lugar a dudas- podrá contemplar un frágil debilitamiento, tanto en su aparato doctrinal como intelectual, al instante en el que desee apartarse del magisterio del "Doctor más universal y el genio más vigoroso que ha poseido la Iglesia". ${ }^{2}$

Así, resulta claro y evidente que, la misma Iglesia- al transcurrir de los siglos- se haya ido basando e inspirando en el pensamiento doctrinal de San Agustín de Hipona (354-430), el "primer hombre moderno" como ya lo denominara Benedicto XVI (1927). ${ }^{3}$

De esta forma, incontables documentos eclesiales se han visto ilustrados y enriquecidos por el magistral pensamiento del gran "genio de Europa". ${ }^{4}$ Entre estos podríamos destacar los denominados "conciliares" (Concilio de Trento (1545-1563), Concilio Vaticano

1 Blondel, Maurice. Dialogues avec les philosohes: Descartes, Spinoza, Malebranche, Pascal, Saint Augustin. Aubier, Paris, 1966, p. 10.

2 Cayré, Fulbert. Initiation a la philosophie de Saint Augustín. Ed. DDB, Paris, 1947, p.3.

3 Ratzinger, Joseph. Cooperadores de la verdad. Ed. Rialp, Madrid, 1991, p. 394.

4 Przywara, Erich. San Agustín. Perfil humano y religioso. Ed. Cristiandad, Madrid, 1984, pp. 21-24. 
I (1869-1870) o el mismo Concilio Vaticano II (1962-1965), entre otros), el Catecismo de la Iglesia Católica (promulgado por el beato Juan Pablo II (1920-2005) y del que nos hallamos celebrando su vigésimo aniversario) o incluso el Directorio para el ministerio y la vida de los presbiteros, en su nueva edición del año 2013, (promulgado por la Congregación para el clero, de la Santa Sede), entre otros varios.

Por otro lado, también la influencia de este "gran hombre y santo"5 se ha dejado sentir tanto en el magisterio como en la propia vida de los Sumos Pontífices. Así, en el siglo XX podriamos citar algunos como Pablo VI (1897-1978) ${ }^{6}$ o el mismo beato Juan Pablo II ${ }^{7}$. Sin embargo, será ya en el siglo posterior cuando se muestre una mayor preponderancia en el magisterio de Benedicto $\mathrm{XVI}^{8}$, preponderancia e influjo de gran notoriedad tanto en homilias, encíclicas, etc.

De esta forma, hemos de advertir que será precisamente tomando como punto de referencia a San Agustín ${ }^{9}$, redacte la encíclica (a modo de "motu propio") Porta Fidei ${ }^{10}$, por medio de la cual se convoca el presente Año de la Fe (11 Octubre 2012-24 Noviembre 2013). Tampoco hemos de obviar las magistrales y edificantes catequesis que, con ocasión de las Audiencias Generales, presenta a los fieles sobre la figura, obra y pensamiento de este "gran santo y doctor de la Iglesia"11, o incluso la obra monográfica que a él dedica. ${ }^{12}$

5 Francisco. Homilia en la Santa Misa de Apertura del Capitulo General de la Orden de San Agustin, 28 Agosto de 2013.

6 Pablo VI. "Discurso en la Inauguración del Instituto Patrístico Augustinianum", en Augustinus, XVI, 1971, pp. 81-84.

7 Juan Pablo II. Augustinum Hipponensem. Libreria Editrice Vaticana, Roma, 1986.

8 "reconozco que yo mismo en los años tempraneros de mi vida y a la hora de tomar las decisiones fundamentales, me senti acompañado muy de cerca por este hombre" (homilia 11 Noviembre de 1979), pues "(es una) figura a la que me siento muy unido por el influjo que ha tenido en mi vida de teólogo, de sacerdote y de pastor" (Audiencia General, 27 Febrero de 2008).

9 Nótese que, únicamente y en toda la encíclica, es tan sólo citado San Agustín entre el numeroso elenco de Santos Padres.

10 Benedicto XVI. Porta Fidei, 11 Octubre de 2011.

11 Benedicto XVI. Audiencia General, 9 Enero de 2008.

12 Ratzinger, Joseph. Pueblo y casa de Dios en la doctrina de la Iglesia en San Agustín. Ed. Encuentro, Madrid, 2012. 
Pero, de igual manera, su Santidad el Papa Francisco (1936) ha vuelto a retomar nuevamente ese "precioso legado" a los que sus predecesores "siempre habian permanecido fieles": el magisterio agustiniano. De esta forma, redacta su primera encíclica Lumen Fidei $^{13}$, en la que (como ya tendremos ocasión de analizar más adelante) uno de los "mejores maestros de la Iglesia"14 vuelve a encontrar su "puesto relevante".

Por tanto, y como clara consecuencia de todo lo expresado anteriormente, deducimos que el Maestro de Tagaste ha estado muy presente tanto en la vida de la Iglesia como en el pensamiento y cultura de todo Occidente. Por todo ello, Benedicto XVI subraya que "es conocido incluso por aquellos que ignoran el cristianismo, o no tienen familiaridad con él"15.

Es de esta manera como "el Doctor de la Gracia" ha dejado una honda y profunda huella en toda la cultura universal. Esta, sin duda, es la única razón que conduce al Papa Emérito a creer que "todos los caminos de la literatura cristiana llevan a Hipona"16, algo que también ya puso de manifiesto el Papa Pablo VI al expresar que "además de brillar en él de forma eminente las cualidades de los Padres, se puede afirmar en verdad que todo el pensamiento de la antigüedad confluye en su obra y de ella derivan corrientes del pensamiento que empapan toda la tradición doctrinal de los siglos posteriores"17.

No obstante, aunque tan sólo se han reseñado los Pontífices más próximos en el tiempo, también podriamos hacer referencia a León XIII (1810-1903) o al mismo Pío XI (1857-1939). Así, mientras aquel subrayó en la encíclica Aeterni Patris ${ }^{18}$ la importancia de sus enseñanzas filosóficas (pues "son de fundamental importancia, no sólo para la historia del cristianismo, sino también para la formación

13 Francisco. Lumen Fidei, 29 Junio de 2013.

${ }_{14}$ Celestino I. Apostolici Verba, PL. 530 A.

15 Benedicto XVI. Audiencia General, 9 Enero de 2008.

16 Benedicto XVI. Audiencia General, 9 Enero de 2008.

17 Pablo VI. "Discurso en la Inauguración del Instituto Patrístico Augustinianum", en Augustinus, XVI, 1971, pp. 81-84.

18 León XIII. Aeterni Patris, 4 Agosto de 1879. 
de toda la cultura occidental", puesto que "es el Padre de la Iglesia que ha dejado el mayor número de obras"19), éste puso de manifiesto en Ad salutem humani generis ${ }^{20}$ que:

"por su ingenio agudisimo, por la riqueza y sublimidad de su doctrina, por la santidad de su vida y por la defensa de la verdad católica nadie, o muy pocos se le pueden comparar de cuantos han florecido desde los principios del género humano hasta nuestros dias"21.

De esta forma, el beato Juan Pablo II no pudo más que expresar, tanto al alumnado como al profesorado del Augustinum, de Roma, su anhelo por hacer que "su doctrina filosófica, teológica y espiritual se estudie $y$ se difunda, de tal modo que continúe...su magisterio en la Iglesia: un magisterio humilde y luminoso al mismo tiempo, que habla sobre todo de Cristo y del amor"22, anhelo este que llevará a Benedicto XVI a pedirle a Dios "que en nuestra vida se nos conceda cada día seguir el ejemplo de este gran convertido, encontrando como él en cada momento de nuestra vida al Señor Jesús, el único que nos salva, nos purifica y nos da la verdadera alegria, la verdadera vida" 23 .

Así, ese "magisterio luminoso" no pudo sino proceder de la propia luz que mana de la fe, luz que inundó e iluminó el "corazón inquieto" 24 agustiniano y que es urgente recuperar para la fe (carácter luminoso) ${ }^{25}$.

Por último, y una vez llegados a este punto, podriamos concluir que el único motivo- tal y como señalamos al comienzo de esta Introducción- por el cual el pensamiento cristiano se podría encontrar debilitado o fortalecido seria: "doctrina sana, id est christiana"26, es

\footnotetext{
Benedicto XVI. Audiencia General, 20 Febrero de 2008.

2 Pio XI. Ad salutem humani generis, 22 Abril de 1930.

1 Pio XI. Ad salutem humani generis, 22 Abril de 1930.

22 Juan Pablo II. Discurso a los profesores y alumnos del Instituto Patrístico Augustinianum, de Roma, 7 Mayo de 1982.

23 Benedicto XVI. Audiencia General, 27 Febrero de 2008.

24 conf. I, 1,1 .

25 Francisco. Lumen Fidei, 4.

26 doc. Chr. IV, 31,64.
} 
decir, su magisterio nos enseña a todos los fieles de la "Católica"27 a saber distinguir y vislumbrar cuál es esta "doctrina sana", la que siempre hemos de seguir, cual es la cristiana.

\section{AGUSTÍN: EL CORAZÓN ILUMINADO POR LA FE}

"iTarde te amé, hermosura tan antigua y tan nueva, tarde te amé! Y he aqui que tú estabas dentro de mí y yo fuera, y por fuera te buscaba; y deforme como era, me lanzaba sobre estas cosas hermosas que tú creaste. Tú estabas conmigo, mas yo no lo estaba contigo. Reteníanme lejos de ti aquellas cosas que, si no estuviesen en ti, no serian. Llamaste y clamaste, y rompiste mi sordera; brillaste y resplandeciste, y curaste mi ceguera; exhalaste tu perfume y respiré, y suspiro por ti; gusté de ti y siento hambre y sed, me tocaste, y abráseme en tu paz". ${ }^{28}$

Es con esta oración (una de las más conocidas y hermosas que aparece en las Confesiones (397-398)) que San Agustín dirige a Cristo, a esa Verdad que buscó tan apasionadamente: lo hizo desde el inicio y durante toda su vida. Sin embargo, "sólo la lectura de las Cartas de San Pablo, en la fe de la Iglesia Católica, le reveló plenamente la verdad"29.

Por todo ello, la mayor aportación que "el Padre común de la Europa cristiana" 30 puede hacer a los hombres de nuestras modernas sociedades es, fundamentalmente, el reconducirlos hacia la verdad, pues como el mismo Maestro de Hipona expresó en una de sus Cartas:

"Me parece que se debe llevar a los hombres a la esperanza de encontrar la verdad"31.

Es esta algo que el hombre necesita para vivir su día a día, pues "sin ella no puede subsistir, no va adelante"32. Sin embargo, podemos

vera rel. 7,12 .

conf. $X, 27,38$.

29 Benedicto XVI. Audiencia General, 27 Febrero de 2008.

Juan Pablo II. Augustinum Hipponensem, II.

ep. 1,1 .

32 Francisco Lumen Fidei, 24. 
apreciar cómo el mundo contemporáneo vive y se desarrolla inmerso en una profunda "crisis de verdad"33.

Y he aquí que, de todo lo expresado anteriormente, se puede extraer "dos grandes ideas", ideas que (recientemente) nos han sido puestas de manifiesto por el Papa Francisco en su primera encíclica Lumen Fidei ${ }^{34}$ : la dimensión eclesial de la fe y la fuerza de la esperanza.

Así, en dicha encíclica- en donde "el Santo de Hipona"35 es mencionado en repetidas ocasiones (once en total)- el Santo Padre incide nuevamente en la "configuración eclesial de la fe"36, algo que ya el mismo San Agustín vivió y apreció con bastante claridad, pues:

"Yo estoy en la Iglesia Católica, cuyos miembros son todas las Iglesias, que, por las Escrituras canónicas, sabemos deben su origen, y también su firmeza, a los trabajos de los apóstoles; según la ayuda que me diere el Señor, no abandonaré su comunión ni en África ni en ninguna parte"37.

De esta forma, él confesó su fe dentro del Cuerpo de Cristo, dentro de la "Católica"38, como comunión con todos los creyentes que- peregrinando por esta vida- se encaminan hacia su patria verdadera, la Jerusalén Celestial o la Ciudad de Dios:

"Sígueme, si puedes; lleguemos juntos a la patria donde ni tú me harás preguntas ni yo a ti. Ahora busquemos juntos creyendo para que después disfrutemos viendo. Alli descansaremos y veremos, veremos $y$ amaremos, amaremos y alabaremos"39.

33 Francisco. Lumen Fidei, 25.

34 "Él ya había completado (Benedicto XVI) prácticamente una primera redacción de esta Carta encíclica. Se lo agradezco de todo corazón y, en la fraternidad de Cristo, asumo su precioso trabajo, añadiendo al texto algunas aportaciones" (Lumen Fidei, 7).

35 Francisco. Lumen Fidei, 33.

36 Francisco. Lumen Fidei, 22.

37 Cresc. 3,35.

38 c. ep Man. 4,5.

39 s. $261,3$. 
Es por todo ello, por su "desmesurado amor y humildad" hacia los fieles de Cristo, por lo que les advertirá han de tener en cuenta que "Para vosotros soy obispo, con vosotros soy cristiano"

De esta manera, la fe debe necesariamente ser vivida y transmitida dentro de la comunidad eclesial, puesto que "es imposible creer cada uno por su cuenta. La fe no es únicamente una opción individual que se hace en la intimidad del creyente, no es una relación exclusiva entre el "yo" del fiel y el "Tú" divino, entre un sujeto autónomo y Dios. Por su misma naturaleza, se abre al "nosotros", se da siempre dentro de la comunión de la Iglesia...Por eso, quien cree nunca está solo, porque la fe tiende a difundirse, a compartir su alegria con otros" ${ }^{\prime 1}$.

Por tanto, San Agustín solamente puede instar a todos sus fieles a "amad esta Iglesia, vivid en tal Iglesia, sed esta Iglesia. Amad al Buen Pastor, hombre tan bello, que a nadie engaña y quiere que todos se salven. Rogad también por las ovejas dispersas; vengan también ellas, reconozcan ellas, amen también ellas, para que haya un solo rebaño y un solo Pastor"42.

Es este "magnifico don"3 que, como bien señala el Papa, la familia (a semejanza de la Iglesia, pues es Ella "una Madre que nos enseña a hablar el lenguaje de la fe" ${ }^{" 4}$ ) debe transmitir. Así, el mismo obispo hiponense cree firmemente que los padres no sólo deberán poseer la "importante y noble misión" de engendrar a los hijos, sino también- fundamentalmente- la de conducirlos y llevarlos a Dios, ${ }^{45}$ pues "la fe está presente en todas las etapas de la vida familiar"46, ya que "la familia no es mas que la vocación que Dios ha escrito en la naturaleza del hombre y la mujer" ${ }^{\text {"7 }}$. De esta manera, él mismo pondrá de manifiesto en sus Confesiones que "bebió el nombre de

40 s. $340,1$.

41 Francisco. Lumen Fidei, 39.

42 s. $139,10$.

43 MA I, 196.

44 Francisco. Lumen Fidei, 38.

45 nupt. et conc. I, 4,5.

46 Francisco. Lumen Fidei, 53.

47 Francisco. Palabras dirigidas a los jóvenes de Asís, 4 Octubre de 2013. 
Cristo con la leche materna"48, algo que coincide totalmente con lo que expresa la Lumen Fidei:

"La fe se transmite, por asi decirlo, por contacto, de persona a persona, como una llama enciende otra llama"49.

Así, la familia cuando vive la alegría de la fe y la comunica, entonces se convierte en sal de la tierra y luz del mundo, en levadura para la sociedad, puesto que no podemos ni debemos permitir que el amor de Dios se apague en ellas, que rompa su armonía ${ }^{50}$.

No obstante, también los sacramentos ("los signos cuando se refieren a cosas divinas" ${ }^{51}$ ) constituyen unos "medios particulares" eficaces para lograr también la transmisión de dicha fe, pues en estos "la Iglesia comunica su memoria" 52 implicando tanto al hombre mismo como a su existencia cristiana.

De entre todos ellos, se ha de destacar especialmente el bautismo, pues gracias a su "acción" nos convertimos en "criaturas nuevas y en hijos adoptivos de Dios" 53 , pues "por el bautismo fuimos sepultados en él a la muerte, para que lo mismo que Cristo resucitó de entre los muertos por la gloria del Padre, asi también nosotros andemos en una vida nueva" ${ }^{54}$. Y, será precisamente esto (la gracia de la vida nueva) lo que el "gran Doctor y Pastor"55subrayará cuando exclame:

"Recibimos el bautismo y se disipó de nosotros la inquietud de la vida pasada. Aquellos dias no me hartaba de considerar con dulzura admirable tus profundos designios sobre la salvación del género humano"56.

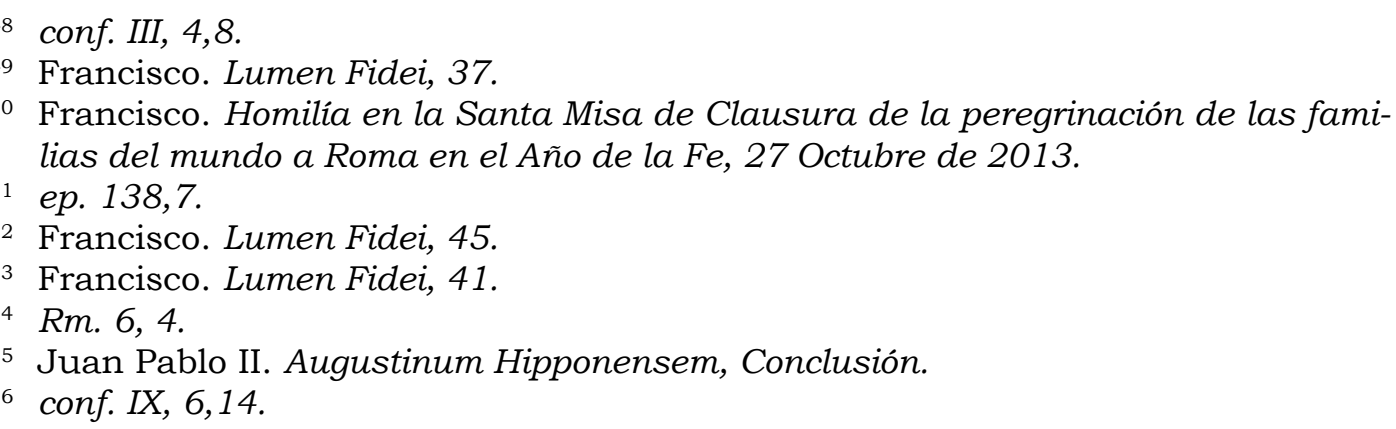


Pero, tengamos en cuenta que dicha salvación nos viene a través de la fe, pues- como bien dirá el apóstol San Pablo (5/10-58/67)"por gracia estáis salvados, mediante la fe. Y esto no viene de vosotros: es don de Dios (Ef. 2, 8s)" "57. Asi, "La fe es un don de Dios", un don sobrenatural que recibimos de El, por lo que "Que nadie se envanezca, que nadie se la atribuya a si" ${ }^{58}$.

Y es, justamente, esta virtud teologal inmersa en la resurrección del Señor, la única capaz de salvarnos, una salvación definitiva y por la que hemos de estar siempre muy unidos a Jesús, pues:

"Jesús no nos ha salvado provisionalmente. inos ha salvado definitivamente!.... y si yo creo que Jesús ha vencido al mal y me salva, debo seguirlo, debo ir por el camino de Jesús toda la vida" ${ }^{\prime 5}$.

De esta forma, el sacramento bautismal constituye también un "camino de esperanza", una esperanza que se abre (gracias a las palabras del ministro y a la acción del agua, puesto que "Suprime las palabras, y ¿qué es el agua sino agua? Une las palabras con el elemento, y se hace sacramento, siendo él también como una palabra visible"60) hacia una vida nueva, es decir, como "un nuevo nacimiento"61.

Así será dicha esperanza la que, como bien nos indica el Sumo Pontifice, "nos proyecta hacia un futuro cierto, que se sitúa en una perspectiva diversa de las propuestas ilusorias de los idolos del mundo", la que nos "da un impulso y una fuerza nueva para vivir cada dia"62, y por ende, la que nunca debemos dejar robar o banalizar (sobre todo "en este periodo de crisis que amenaza la esperanza"63). De esta forma, el Maestro africano cree que también "en esta vida es desgracia no tener esperanza, pues quien no la tiene no poseerá después la bienaventuranza" 64 .

57 Francisco. Lumen Fidei, 19.

58 s. $168,8$.

59 Francisco. Palabras dirigidas a los jóvenes de Asis, 4 Octubre de 2013.

60 Jo ev.tr. 80, 3.

61 Francisco. Lumen Fidei, 43.

62 Francisco. Lumen Fidei, 57.

${ }_{63}$ Francisco. Palabras dirigidas a los jóvenes de Asís, 4 Octubre de 2013.

64 ep. 129, 10. 
Por todo ello, y con especial relevancia para los tiempos presentes en los que muchas veces "falta la luz y todo se vuelve confuso" haciendo "imposible distinguir el bien y el mal""5 ("iTenemos necesidad de salvación! ¿Salvación de qué? Del mal...el mal no es invencible y el cristiano no se resigna ante el mal...Dios es más grande que el mal") 66 , el cristiano que "intenta reconocer los signos de Dios en las experiencias cotidianas de su vida" y se halla "en camino"67 deberá volcar toda su atención en este "sabio consejo agustiniano":

"Aprended y retened lo qué es la esperanza cristiana, por qué somos cristianos. No somos cristianos por buscar una felicidad terrena, que a veces no les falta a los ladrones y criminales. Somos cristianos por buscar otra felicidad, que recibiremos cuando se termine enteramente esta vida del siglo"68.

Pero, como hemos advertido anteriormente, la vida de todo fiel cristiano no consiste sino en "caminar","un peregrinaje que nos conducirá hasta la culminación de nuestra esperanza, pues "la vida que no es eterna no merece llamarse vida, puesto que vida verdadera no lo es mas que la eterna (...) porque es la única que es feliz"69.

Así, y mientras vamos de camino "cantemos al Señor en nuestra vida; nuestra vida ahora es esperanza, después será eternidad. La vida de la vida mortal es la esperanza de la vida inmortal"70. Nuestro camino no es otro que el de la oración ("el clamor del corazón"), ya que "Orar y caminar en la Iglesia van unidas, se entrelazan.....Este es el camino: llevar el Evangelio a través del testimonio de nuestra vida"71.

De igual manera, "La fe, que recibimos de Dios como don sobrenatural, se presenta como luz en el sendero, que orienta nuestro

65 Francisco. Lumen Fidei, 3.

66 Francisco. Palabras dirigidas a los jóvenes de Asís, 4 Octubre de 2013.

67 Francisco. Lumen Fidei, 35.

68 ep. 62, 6.

69 s. 346,1

70 ep. 103/s. 4, 17.

71 Francisco. Palabras dirigidas a los jóvenes de Asis, 4 Octubre de 2013. 
camino en el tiempo"72. Así, como bien nos señala el Papa, "La fe es a la llamada a un largo camino para adorar al Señor en el Sinaí y heredar la tierra prometida"73.

No obstante, "Porque creiste, esperaste y porque esperaste, amaste" ${ }^{74}$, es decir, las virtudes teologales- y según el pensamiento agustiniano- quedan encadenadas unas a otras. Sin embargo, será la caridad ("la virtud del alma"75) la que "englobe", "asuma" a las otras restantes (fe y esperanza), ya que:

"Donde está la caridad, está también la fe y la esperanza"76.

De esta forma, será dicha caridad la virtud que nos permita el poder llegar a la plena visión y al goce absoluto de la Ciudad de Dios, mientras que la fe y la esperanza sólo serán necesarias mientras nos encontremos disfrutando de esta vida temporal:

“...luego, tres condiciones son necesarias al alma: que esté sana, que mire, que vea. Las otras tres: fe, esperanza y caridad, son indispensables para lo primero y segundo. Para conocer a Dios en esta vida, igualmente las tres son necesarias; y en la otra vida sólo subsiste la caridad"77.

Por ello, el Papa Francisco manifiesta que "la fe se abre al amor"78, que la verdad (que se manifiesta a través de la fe) necesita a aquél, pero- a la vez- aquél (el amor) también necesita de esta (la fe). Así, al mismo tiempo (y como bien señala el Santo Padre):

"la fe es un don gratuito de Dios que exige la humildad"79, una humildad que tan sólo nos la podrá otorgar la caridad, puesto que "Donde hay caridad, hay paz, y donde hay humildad, caridad"80.

Francisco. Lumen Fidei, 4.

${ }^{73}$ Francisco. Lumen Fidei, 12.

${ }^{74}$ en. Ps. $114,2$.

75 s. $2,3$.

76 Jo.ev.tr. 83, 3.

77 sol. I, 7,14 .

78 Francisco. Lumen Fidei, 27.

79 Francisco. Lumen Fidei, 14.

80 ep.Jo. 1, 1. 
Por lo tanto, bien podemos deducir que "este don sobrenatural que recibimos de El" 81 no es apto para los soberbios, pues "el hombre religioso...ha de estar dispuesto a dejarse guiar"82, ya que "la fe consiste en la disponibilidad para dejarse transformar una y otra vez por la llamada de Dios" ", puesto que:

"Por la soberbia caimos para llegar a esta mortalidad. Y porque la soberbia nos habia herido, la humildad nos hace sanos. Vino Dios humilde para curar al hombre de tan grande herida de la soberbia" ${ }^{4}$.

Así, él mismo nos confesará que "Yo que os hablo, estuve engañado un tiempo, cuando de joven me acerqué por primera vez a las Sagradas Escrituras. Me acerqué a ellas no con la piedad del que busca humildemente, sino con la presunción de quien quiere discutir... ¡Pobre de mí, que me creí apto para el vuelo, abandoné el nido y cai antes de poder volar!"85.

Por todo ello, nos podríamos plantear la cuestión en torno a la soberbia. Esta se define como "la madre de todos los herejes"86, "el gorgojo de las riquezas", ${ }^{87}$ aquella por la que Dios se hace hombre, puesto que "nació humilde del Espiritu Santo y de la Virgen Maria para sanar a los soberbios"88.

De esta forma, "dicho pecado" ("la puerta del infierno"89, la que nos impide "ver el camino luminoso del encuentro entre Dios y los hombres"90) constituye el único y principal obstáculo para poder llevar a cabo la conversión, un obstáculo que- a veces- inunda nuestra alma de grandes inquietudes.

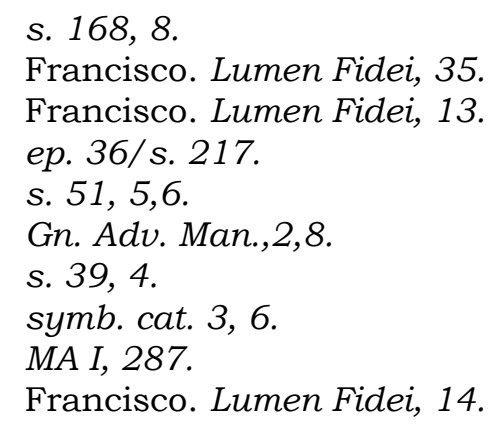




\section{UN ALMA INUNDADA POR GRANDES INQUIETUDES}

"Y tú, Señor ¿hasta cuándo? ¿Hasta cuándo, Señor, has de estar irritado? No quieras más acordarte de nuestras inquietudes antiguas"91. “¿Dónde estabas entonces y cuán lejos de mí? Yo vagaba lejos de Ti...y tú, por el contrario, estabas más dentro de mi que la parte más profunda de mí mismo y más alto que la parte más alta de mí mismo"92, pues, "tú estabas conmigo, pero yo no estaba contigo"

Inquietud y conversión, conversión e inquietud, dos grandes palabras que sintetizan toda la vida de San Agustín de Hipona. Será justamente en la primera de estas que, tomando como punto de referencia la homilia del Santo Padre Francisco para la Santa Misa de apertura del capitulo general de la orden de San Agustin (28 Agosto de 2013), centraremos el análisis de nuestras reflexiones posteriores.

En primer lugar se ha de advertir que- con mero carácter anecdótico- para el Papa Francisco existirán al menos tres tipos diferentes de inquietudes "en la vida de tan insigne Doctor" 94 , mientras que- de igual modo- volverán a ser tres las conversiones que- según Benedicto XVI- la vida agustiniana ha sufrido:

"El camino de conversión de San Agustín continuó humildemente hasta el final de su vida, y se puede decir con verdad que sus diferentes etapasse pueden distinguir fácilmente tres- son una única y gran conversión" ${ }^{\prime \prime}$.

Pero, analizando nuevamente las inquietudes que el Obispo de Hipona experimenta en su vida, el Santo Padre advierte y señalafundamentalmente- estas tres:

"inquietud de la búsqueda espiritual, inquietud del encuentro con Dios e inquietud del amor"96.

91 conf. VIII, 12,28.

92 conf. III, 6,11 .

93 conf. $X, 27,38$.

${ }^{94}$ Francisco. Homilia de la Santa Misa de apertura del capitulo general de la orden de San Agustin, 28 Agosto de 2013.

95 Benedicto XVI. Audiencia General, 27 Febrero de 2008.

96 Francisco. Homilía en la Santa Misa de apertura del capitulo general de la orden de San Agustín, 28 Agosto de 2013. 
En contraste, y como ya dijimos anteriormente, Benedicto XVI atisbó "tres tipos de conversiones agustinianas":

"acercamiento progresivo, pasión que lo lleva a buscar a Dios y la que lo llevó a pedir a Dios perdón cada día de su vida" ${ }^{37}$.

Será justamente esta inquietud de corazón la que desemboque en su conversión, un "gesto" por el que- sin duda- hemos de brindar "una acción de gracias a Dios por el don que hizo a la Iglesia, y mediante ella a la humanidad entera, gracias a aquella admirable conversión"98.

En primer lugar, el Papa Francisco advierte en "uno de los más grandes convertidos de la historia cristiana" una primera inquietud de indole espiritual. Aunque el "retórico africano"100 lo poseía todo en su vida (fama, éxito, poder, etc), sin embargo "en su corazón permanece la inquietud de la búsqueda del sentido profundo de la vida"101. Así, su corazón- lejos de estar adormilado o "anestesiado"102_ continúa buscando la verdad, el rostro de Dios:

"Vayamos en su busca para alcanzarle, y busquémosle después de hallarlo. Para que le busquemos, se oculta, y para que le sigamos buscando, aún después de hallarle, es inmenso...El llena los deseos según la capacidad del investigador. Y al que lo halla le hace más capaz para que de nuevo quiera llevarse según su mayor capacidad"103.

De esta forma, la verdad siempre habla en nuestro interior, no distinguiendo entre buenos y malos:

"Dios habla también en la conciencia de los buenos y de los malos. Porque el aprobar lo que está bien hecho y conservar lo malo, no se puede sin la voz de aquella verdad que en el silencio del corazón da su juicio de aprobación o condenación"104.

97 Benedicto XVI. Audiencia General, 27 Febrero de 2008.

98 Juan Pablo II. Augustinum Hipponensem, 1.

99 Benedicto XVI. Audiencia General, 27 Febrero de 2008.

100 Benedicto XVI. Audiencia General, 28 Febrero de 2008.

${ }^{101}$ Francisco. Homilia en la Santa Misa de apertura del capitulo general de la orden de San Agustin, 28 Agosto de 2013.

${ }^{102}$ Francisco, ibid.

103 Jo.ev.tr. 61, 1.

104 s. $12,4$. 
Por otro lado, y puesto que él "no se encierra en sí mismo... descubre que Dios le esperaba; más aún, que jamás habia dejado de buscarle El primero"105, pues la persona que encuentra a Dios sigue aún buscándole, puesto que "Mi alma tiene sed de ti"106.

Así, “¿Acaso seguiremos buscándole después de encontrarle? De esa manera hay que buscar las cosas incomprensibles, para que no piense que no ha encontrado nada el que averiguó cuán incomprensible es lo que buscó. Pues, ¿cómo vamos a buscar lo que sabemos que es incomprensible sino porque no hemos de dar de mano a la búsqueda, mientras la misma investigación de lo incomprensible nos haga progresar y mejorarse más y más, yendo en pos de un tan grande Bien, al que se le busca para hallarlo, y con el hallazgo enciende el deseo de buscarlo? Pues se le busca para encontrarlo dulcemente, y se le encuentra para buscarle con más avidez. Así se ha de entender el lugar del Eclesiástico donde dice la Sabiduria: "Quienes me aman tendrán hambre y quienes me beban tendrán sed" (Si. 24, 21). Comen pues, y beben, porque encuentran, y porque tienen hambre y sed, todavía siguen buscando. La fe busca, el entendimiento halla"107.

De esta forma, y según el Santo Obispo, todos los seres racionales deberán subyugar sus vidas a la "Verdad Inmutable", pues de lo contrario se tornarán en "desgraciadas y desdichadas":

"Toda vida racional, si es perfecta, se somete a la verdad inmutable, que habla en la conciencia interiormente sin ruido $y$, si no se somete a ella, se hace viciosa"108, pues "al retirarse de ella, el alma se oscurece; cuando se acerca se ilumina"109.

Por lo tanto, "Siendo pequeño y flaco el entendimiento del hombre, debe rendirse a la verdad divina"110, una verdad que- sin

\footnotetext{
${ }^{105}$ Francisco. Homilia en la Santa Misa de apertura del capitulo general de la orden de San Agustín, 28 Agosto de 2013.

106 Sal. 62.

107 Trin. $X V, 2,2$.

108 vera. relg. 55, 110.

109 en. Ps. 58, 18.

110 ep. 102, 14.
} 
duda- lo conducirá a su encuentro con Cristo ${ }^{111}$ (segunda inquietud señalada por el Papa).

Así, "La fe en el Hijo de Dios hecho hombre en Jesús de Nazaret no nos separa de la realidad, sino que nos permite captar su significado profundo, descubrir cuánto ama Dios a este mundo y cómo lo orienta incesantemente hacia si; $y$ esto lleva al cristiano a comprometerse, a vivir con mayor intensidad todavia el camino sobre la tierra"112.

San Agustín, movido por esta santa inquietud, desea y anhela conocer cada vez más y más a Dios, puesto que también pretende transmitirla a los demás. Por ello, quiere "ser la imagen de Jesús Buen Pastor"113, no cansándose nunca de anunciar al Señor, de "evangelizar con valentia"114. Así, con el apóstol San Pablo bien pudo exclamar: "¡Ay de mi si no predicara el Evangelio!"115, o quizás- como señala el Santo Padre- "anuncia la palabra, insiste en el momento oportuno y no oportuno, enseña el evangelio con el corazón magnánimo, grande (cf. 2 Tim. 4,2) de un Pastor que está inquieto por sus ovejas"116.

De esta forma, el Papa cree vislumbrar como una cierta "tensión" en el obispo hiponense, puesto que buscando a Dios incesantemente sale al encuentro del rebaño, de los fieles cristianos, ya que "Nuestro camino quiere caminantes. A tres clases de hombres aborrece: al que está quieto, al que retrocede, al que anda fuera de El. Guarde y defienda el Señor nuestros pasos de estos tres malos géneros de hombres"117.

Y será esta búsqueda del rebaño del Señor, la que lo conduciráinexorablemente- a la tercera y última inquietud vivida en su corazón: la inquietud del amor.

${ }^{111}$ Francisco. Homilia en la Santa Misa de apertura del capitulo general de la orden de San Agustín, 28 Agosto de 2013.

112 Francisco. Lumen Fidei, 18.

${ }^{113}$ Francisco. Homilia en la Santa Misa de apertura del capitulo general de la orden de San Agustín, 28 Agosto de 2013.

${ }^{114}$ Francisco. Homilia en la Santa Misa de apertura del capitulo general de la orden de San Agustín, 28 Agosto de 2013.

1151 Cor. 9, 16.

116 Francisco. Ibid.

117 De cantico nove, 4. 
Dicha inquietud, heredada de su madre Mónica de Tagaste (332-387), no consistirá sino en salir de sí mismo para poder así, adentrarnos en el otro- teniendo en cuenta siempre su bien-. A veces, la intensidad con la que esta se vive podrá desembocar en las lágrimas ("la sangre del corazón"118). Claros ejemplos, y según señala el Papa, los tendríamos en los siguientes pasajes evangélicos:

"Jesús llora ante el sepulcro de su amigo Lázaro"119, "Pedro que, tras haber negado a Jesús, encuentra la mirada rica en misericordia y de amor y llora amargamente"120 o "la Virgen María que con amor sigue a su Hijo Jesús hasta la cruz"121.

Sería "la fecundidad pastoral", la que- y según indica el Sumo Pontífice- podría corroborar el buen funcionamiento de la mencionada inquietud. Dicha "fecundidad", sólo podremos lograrla siendo audaz y capaz de administrar a las "ovejas" lo que cada una demande, pues: "Da leche a los párvulos, para dar comida de sabiduría a los mayores. El párvulo no puede con la comida que hay en la mesa; y ¿qué hace la madre? Encarna la comida y la convierte en leche. Hace lo que podemos tomar. Asi, el Verbo se hizo carne para que nos alimentásemos de leche los que no podiamos, por ser infantes, con la comida"122, puesto que todos (pequeños y mayores) integramos una sola y única Iglesia, "todos estamos embarcados":

"La Iglesia de Dios tiene almas fuertes, tiene almas flacas; no pueden faltar en ella los fuertes ni los débiles"123.

Así, podriamos afirmar que estas tres inquietudes agustinianas, constituirian- a su vez- un reflejo de las tres virtudes teologales: fe (representada en la "búsqueda espiritual"), esperanza (representada en el "encuentro con Dios") y caridad (representada en la "inquietud

\footnotetext{
118 conf. $V, 10-13$.

119 Jn. 11, 35.

120 Lc. 22, 62.

121 Jn. 19, 25.

122 s. $117,16$.

123 s. $76,3$.
} 
del amor"), pues "El que cree, espera y ama, no por eso simplemente ha de tenerse por salvo; por que importa qué cree, qué espera y qué ama, pues nadie vive en cualquier forma de vida sin estas tres afecciones del alma"124.

Por todo ello, Benedicto XVI lo definió como "un hombre de pasión $y$ de fe, de altisima inteligencia y de incansable solicitud pastoral"125.

\section{IDENTIDAD Y SERVICIO DEL MAGISTERIO AGUSTINIANO}

"No será inoportuno dedicar un recuerdo a la acción pastoral de este obispo a quien nadie encontrará dificultad de catalogar entre los más grandes Pastores de la Iglesia"126.

De esta forma, el beato Juan Pablo II calificaba su ministerio pastoral, un ministerio concebido como una total y entera entrega al servicio de Dios ("Ya no amo más que a Ti...y a Ti sólo quiero servir"127) y, por ende, a la Iglesia ("siervo de los siervos de Cristo"128), tanto local como universal.

En cuanto a aquélla, su diócesis de Hipona (de la que "nunca se alejó, sino por necesidad"129), fue asiduo en la predicación, en la catequesis, en la "audientia episcopi" (en las que a veces olvidaba hasta de comer), en el cuidado de los pobres, en la formación del clero, en la guía de los monjes y de los monasterios, entre otras.

Y en cuanto a la Iglesia universal, "dejó un clero muy numeroso, así como también monasterios de hombres y mujeres repletos de personas consagradas a la continencia bajo la obediencia de sus superiores, además de bibliotecas..."130 .

\footnotetext{
124 s. $198,2$.

${ }^{125}$ Benedicto XVI. Audiencia General, 9 Enero de 2008.

126 Juan Pablo II. Augustinum Hipponensm, III.

127 Sol. I, 1,5.

128 ep. 217.

129 ep. 122.

130 Posidio. Vita S. Augustini, 31, 8.
} 
A todo ello, hemos de añadirle el ministerio de la predicación ("dondequiera que le llamaran"131), su presencia en los distintos Concilios (Cartago (397, 401, 404) Milevi (415)), composición de numerosas obras y cartas, pero- sobre todo- cabe destacar las innumerables controversias que- a lo largo de su vida- sostuvo contra los herejes que asediaban a la Iglesia Católica:

"No están todos los herejes por toda la tierra, pero hay herejes en toda la superficie de la tierra....En países diversos hay diversas herejias, pero todas tienen por madre la soberbia, como nuestra única madre católica engendró a todos los fieles cristianos repartidos por el mundo. No es extraño, pues, que la soberbia engendre división, mientras la caridad es madre de la unidad"132.

De esta manera, y para ayudar al presbítero a alcanzar una ciertacomo nos señaló el Papa- "fecundidad pastoral", la Congregación para el clero nos ofrece una nueva edición del Directorio para el ministerio y vida de los presbiteros. Dicha edición, que es "más congenial al momento presente"133, se ha visto enriquecida por "el rico Magisterio más reciente"134. Así, todo ello hace de este documento "un nuevo instrumento adecuado para arrojar luz y servir de guía en el compromiso de renovación espiritual de los ministros sagrados, apóstoles cada vez más desorientados, inmersos en un mundo dificil y continuamente cambiante", ya que "es un documento de edificación y santificación de los sacerdotes en un mundo en gran parte secularizado e indiferente"135.

No obstante, el presbitero nunca debe olvidar que "nadie debe vivir tan ocioso, que no piense en la utilidad del prójimo; ni debe ser tan activo que abandone la contemplación de Dios"136.

También debe tener en cuenta que, a veces, "los mismos fieles corren el riesgo de olvidar que el cristianismo es una religión más del

\footnotetext{
${ }^{131}$ Retract., prol. 2.

132 s. $46,18$.

${ }^{133}$ Congregación para el Clero. Directorio para el ministerio y la vida de los presbiteros. Ed. Edice, Madrid, 2013, Presentación, p. 8.

${ }^{134}$ Congregación para el Clero, ibid., Presentación, p. 14.

${ }^{135}$ Congregación para el Clero. ibid., Presentación, p. 8.

136 civ. Dei XIX, 19.
} 
espiritu que del corazón. Por eso mismo, es preciso formar no sólo santos, sino también sabios, y como la ciencia se halla sobre todo en los clásicos, a ellos es a quienes los clérigos deben acudir"137.

Por otro lado, en el origen de la nueva edición de este documento, está también "lamentablemente, las dolorosas heridas que han atormentado a la Iglesia por la conducta de algunos de sus ministros"138.

Ante ello, el "gran Obispo y Doctor"139 exhorta a todos, y especialmente al presbitero, a "Vivir honradamente dentro de la Iglesia, pues viviendo bien en esta Iglesia, ningún daño te acarrearán los pecados de otros miembros, porque en ella, no obstante esta unidad, cada uno responderá de sus actos y sufrirá el castigo por ellos merecido"140, al mismo tiempo que siempre deberá "amar a la Iglesia Católica, amar a la Iglesia de Cristo, porque amando a la Iglesia de Cristo recibes el Espiritu Santo"141.

En definitiva:

"Ama a tu Dios y Señor y ama a su Iglesia: ama a Dios como Padre y a la Iglesia como madre; ama a Dios como señor, a la Iglesia como a su sierva; porque tú eres hijo de su sierva"142.

De esta forma, poseemos suficientes razones para retomar de nuevo el estudio de los Santos Padres, especialmente a San Agustín, en este documento para el clero.

Es por ello, por lo que varias páginas de este son ilustradas con el magisterio agustiniano, un documento que tan sólo desea "constituir para todo hombre llamado a participar en el sacerdocio de Cristo, Cabeza y Pastor, una ayuda para profundizar la propia

${ }^{137}$ Combés, Gustave. Saint Augustin et la culture classique”. Plon, París, 1927, p. 118.

138 Congregación para el Clero. ibid., p. 8.

139 Pio XI. Ad salutem hamani generis, 20 Abril de 1930.

140 ep. 141, 6.

141 Jo.ev.tr. 23, 7.

142 en. Ps. 88, 2, 14. 
identidad vocacional y acrecer la propia vida interior;... un punto de referencia para un apostolado rico y auténtico, en beneficio de la Iglesia y del mundo entero"143.

El Papa emérito Benedicto XVI, al convocar el Año de la Fe, nos exhortó a llevar a cabo en nuestras vidas una profunda conversión, puesto que- actualmente- se hace muy necesario un cierto compromiso eclesial que aliente a la nueva evangelización:

"Hoy es necesario un compromiso eclesial más convencido a favor de una nueva evangelización, para redescubrir la alegria de creer y volver a encontrar el entusiasmo de comunicar la fe"144, puesto que no hemos de olvidar que "a lo largo de este año, será decisivo volver a recorrer la historia de nuestra fe, que contempla el misterio insondable del entusiasmo de la santidad y el pecado. Mientras lo primero pone de relieve la gran contribución que los hombres y mujeres han ofrecido para el crecimiento y desarrollo de las comunidades a través del testimonio de su vida, lo segundo debe suscitar en cada uno un sincero y constante acto de conversión, con el fin de experimentar la misericordia del Padre que sale al encuentro de todos"145.

Sin embargo, ya el beato Juan Pablo II nos advirtió que "la llamada a la nueva evangelización es sobre todo una llamada a la conversión"146, conversión que apremia y urge a nuestro espíritu. Por tanto, "No digas, pues: Mañana me convertiré, mañana contentaré a Dios, $y$ de todos mis pecados pasados y presentes quedaré perdonado. Dices bien que Dios ha prometido el perdón al que se convierte, pero no ha prometido el dia de mañana a los perezosos"147.

Y es justamente a esta conversión a la que el sacerdote está llamado de una manera especial, puesto que "No podemos aqui ser perfectos sin tener conciencia de que no podemos serlo. Quien presume de serlo ya se pone en lo alto para caer"148.

\footnotetext{
${ }^{143}$ Congregación para el Clero. ibid., p. 17.

${ }^{144}$ Benedicto XVI. Porta Fidei, 7.

145 Benedicto XVI. Porta Fidei, 13.

146 Juan Pablo II. Discurso Inaugural en la IV Conferencia General del Episcopado Latinoamericano, 1 .

147 en. Ps. $144,13$.

148 en. Ps. 38, 14.
} 
De esta forma, "en la nueva evangelización, el sacerdote está llamado a ser "heraldo de la esperanza""149, es decir, aquel que muestra a todos hacia dónde debemos enfocar nuestra esperanza, una esperanza que sólo hallaremos en Dios, ya que "nuestra esperanza, sea nuestro Dios"150.

San Agustín, "una de las figuras más grande en la historia del pensamiento"151, se erige para el presbítero como el modelo de Pastor que sabe alentar y exhortar a sus fieles a aguardar la auténtica espera, pues "Os suplico a vosotros: amad conmigo, corred conmigo con la fe; deseemos la patria de arriba, suspiremos por la patria de arriba, y aqui sintámonos peregrinos. ¿Qué veremos entonces? Dígalo el evangelista: "En el principio era el Verbo, y el Verbo estaba con Dios, y Dios era el Verbo""152.

Igualmente lo hace cuando comunica a sus fieles que "el caminante, cuando se fatiga andando soporta el cansancio, porque espera llegar. Quitale la esperanza de la llegada, y se le cae el alma a los pies. Luego la esperanza que tenemos aqui pertenece a la exigencia de nuestra peregrinación"153.

Por otro lado, también el Santo Padre Francisco manifiesta (como podemos leer en su primera encíclica Lumen Fidei (29 Junio 2013)) ciertas ideas que corren paralelas a las ya citadas palabras agustinianas, pues nos comenta que “.., la fe va de la mano de la esperanza porque, aunque nuestra morada terrenal se destruye, tenemos una mansión eterna que Dios ha inaugurado ya en Cristo, en su cuerpo (cf. 2 Co.4, 16-5, 5). El dinamismo de fe, esperanza y caridad (cf. 1 Ts. 1, 3; 1 Co. 13, 13) nos permite asi integrar las preocupaciones de todos los hombres en nuestro camino hacia aquella ciudad "cuyo arquitecto y constructor iba a ser Dios" (Hb. 11, 10), porque "la esperanza no defrauda" (Rm. 5, 5)"154.

\footnotetext{
149 Juan Pablo II. ibid., 25.

150 en. Ps. 38, 8.

${ }^{151}$ Benedicto XVI. Audiencia General, 27 Febrero de 2008.

152 Jo.ev.tr. 35, 8.

153 s. $158,8$.

${ }^{154}$ Francisco. Lumen Fidei, 57.
} 
Así, la vida, identidad, ministerio y formación del presbítero va a depender, entre otros factores, de la esperanza ${ }^{155}$, puesto que "Ningún hombre vive sin esperanza"156.

De esta forma, él "enciende su lámpara en la esperanza", hace ver y comprender a los cristianos que nuestra esperanza se proyecta en un "mundo futuro"157 donde "Dios será todo en todos"158:

"Dios será el fin de nuestros deseos, pues le veremos sin fin, le amaremos sin fastidio, lo alabaremos sin cansancio. Este oficio, este afecto, este acto, será, sin duda, como la misma vida eterna, común a todos"159, pues es esta la "única razón del ser cristiano"160.

Por todo ello, el Directorio para el ministerio y la vida de los presbiteros concluye afirmando que "el sacerdote está llamado a elevar al hombre engendrándolo a la vida divina y haciéndolo crecer en la relación con Dios hasta llegar a la plenitud de Cristo,...pues debe presentarse al mundo como modelo de vida sobrenatural"161, por lo que (el presbitero) debe emplear todas sus fuerzas en ayudar a sus hermanos. En ello, encontrará un medio para su santificación, a la vez que otorgará la mayor gloria a Dios:

“...y máxime sabiendo también de antemano que de la raza de los mortales habian de surgir santos que buscarian la gloria de Dios y no la suya"162.

Por lo tanto, el "operario de Dios" debe trabajar sin fisura y sin medida alguna en las obras del Señor, en aquellas que conducen hacia la vida eterna, pues:

"Ejercitate en las obras, trabaja en la viña; al terminar el día, pide el salario"163, ya que "eres operario de Dios"164.

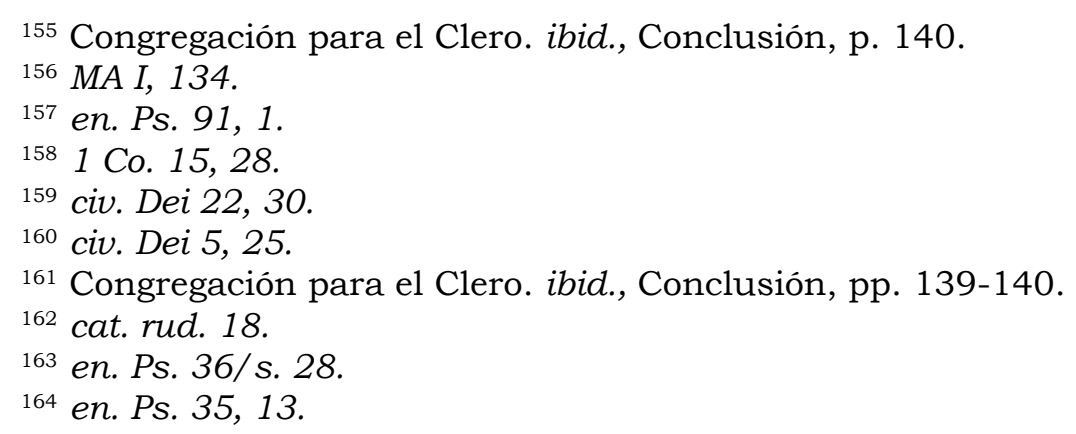




\section{CONCLUSIÓN}

"Toda la escolástica, a pesar de sus altas cimas, va a depender en lo esencial de San Agustín"165.

En verdad, hemos podido comprobar y ratificar que es el Maestro de Hipona, no sólo uno de "los más grandes Pastores de la Iglesia"166 sino también (y como ya se advirtió anteriormente), "una de las figuras más grandes en la historia del pensamiento"167.

Tampoco hemos de obviar que su marcado influjo en la Iglesia universal (en todos los tiempos), tanto filosófico como teológico, ha sido y es de un "profundo calado". Al mismo tiempo, su inigualable magisterio ha constituido una fuente de inspiración tanto para Pontífices como para numerosos documentos eclesiales.

De esta forma, la única explicación que podamos ofrecer a todo esto será- seguramente- la enseñanza de un "método teológico" firme y seguro, método al que siempre se mantuvo fiel, método que no consistió más que en la adhesión "plenamente a la autoridad de la fe que se pone de manifiesto a través de la Escritura, la Tradición y la Iglesia"168.

Es la Escritura, por lo tanto, como una especie de "altavoz" a través de la cual los hombres podemos escuchar la voz de Dios, pues él mismo así lo cree, ya que "cuando lees, Dios te habla; cuando oras, tú hablas a Dios"169. Sin embargo, esta también ejerce la noble función de reflejar el rostro del hombre, pudiéndolo llegar- inclusoa "recomponerlo" cuando esté desfigurado y deforme:

"La Escritura es para ti como un espejo. Tiene un esplendor que no engaña, que no adula, que no acepta personas. Eres hermoso: él refleja tu hermosura; eres feo: te hace ver tu fealdad. Mas, si eres deforme, deformes te ves en él, no tires el espejo, sino vuelve en ti; él no te engaña; no quieras engañarte tü"

\footnotetext{
${ }^{165}$ Marias, Julián. Historia de la filosofia. Revista de Occidente, Madrid, 1980, p. 116.

166 Juan Pablo II. Augustinum Hipponensem, II.

${ }^{167}$ Benedicto XVI. Audiencia General, 27 Febrero de 2008.

168 Juan Pablo II. Augustinum Hipponensem, IV.

169 en. Ps. 85, 7.

170 s. $48,5$.
} 
De esta forma, él comprendió que la autoridad de Cristo se hallaba en dichas Escrituras ${ }^{171}$, las cuales eran refrendadas por la misma autoridad de la Iglesia Católica ${ }^{172}$, unas Escrituras quesin embargo- al principio "le decepcionaron, no sólo porque el estilo latino de su traducción era deficiente, sino también porque el mismo contenido no le pareció satisfactorio"173. Por todo lo cual, podemos llegar a afirmar con Benedicto XVI que "pocas veces una civilización ha encontrado un espiritu tan grande, capaz de acoger sus valores y de exaltar su riqueza intrinseca, inventando ideas y formas de las que se alimentarian las generaciones posteriores"174.

No obstante, se alzan voces que ponen de manifiesto el "injusto tratamiento que la misma historia ha otorgado a este Obispo de Hipona, al que tan sólo "ha sabido acercarle mas que con la aureola del "más santo entre los sabios"- piedad-cuando no "el más sabio entre los santos"- teología"175. No obstante, San Agustín no necesita de ningún "apoyo" para conseguir su "fama señera"176.

Así, conscientes de esa importancia trascendental que el Santo Obispo y Doctor comporta, ya no sólo para la Iglesia universal sino también para toda la vida cultural e intelectual del mundo latino, el beato Juan Pablo II insta a "los hijos espirituales del Santo" (aquellos que han retomado su legado) para que mantengan "vivo y atrayente el encanto de San Agustín también en la sociedad moderna", ideal estupendo y entusiasmante, porque "el conocimiento exacto y afectuoso de su pensamiento y de su vida provoca la sed de Dios, descubre el encanto de Jesucristo, el amor a la sabiduría y a la verdad, la necesidad de la gracia, de la oración, de la virtud, de la caridad fraterna, el anhelo de la eternidad feliz"177.

\footnotetext{
171 conf. VI, 5, 7; VI, 11, 19.

172 conf. VII, 7,11.

${ }^{173}$ Benedicto XVI. Audiencia General, 9 Enero de 2008.

${ }^{174}$ Benedicto XVI, .ibid.

175 Álvarez Turienzo, Saturnino. "San Agustín, Escritor. La renovación de un lenguaje”, en La Ciudad de Dios, Vol. CLXVI, pp. 233-255.

176 Âlvarez Turienzo, Saturnino. ibid., p. 233.

177 Juan Pablo II. Discurso al capitulo general de la orden de San Agustín, 25 Agosto de 1983.
} 
Por otro lado, también el Papa Pío IX (1792-1878) llegó a calificarlo como aquella "persona a la que casi nadie o muy pocas de cuantas han florecido desde el principio del género humano hasta hoy se le pueden comparar"178. Es por ello que Johannes Quasten (1900-1987) lo ha tildado del "más grande de los Padres y uno de los genios más eminentes de la humanidad"179, pues:

"Unía en sí este gran obispo la potencia creadora de Tertuliano, la vasta inteligencia de Orígenes, con el profundo amor de Cipriano a la Iglesia; la aguda dialéctica de Aristóteles, con el idealismo alado de Platón; el sentido práctico de los latinos, con la inteligencia especulativa de los griegos. Por esto es, sin duda, el más grande filósofo de la época patrística, y hasta se puede afirmar que el más importante e influyente teólogo de toda la Iglesia..., ya que lo que fue Orígenes para la ciencia teológica de los siglos III y IV, ha sido Agustín, aunque de un modo más puro y eficaz, para toda la vida de la Iglesia universal a través de los siglos hasta nuestros días. Su influencia se ha dejado sentir, no sólo en la filosofia, teología moral y mística, sino también en la vida social, en la politica eclesiástica, en el derecho civil; en una palabra, fue el gran artifice de la cultura occidental del medioevo"180.

Por último, tan sólo podemos finalizar haciéndonos eco de las palabras con las que el beato Juan Pablo II concluye su Carta Apostólica:

"manifiesto el vivo deseo de que se estudie y sea ampliamente conocida su doctrina y de que se imite su celo pastoral, para que el magisterio de tan gran Doctor y Pastor continúen en la Iglesia y en el mundo entero en beneficio de la cultura y de la fe"181.

Así, San Agustín será siempre "el perenne candil que ilumina a la Iglesia". Por todo ello, "gracias sean dadas a Dios"182.

\footnotetext{
178 AAS. 22, 223.

179 Quasten, Johannes. Patrología II. La edad de oro de la literatura latina. Ed. BAC, Madrid, 1993, c. VI, pp. 405-553.

${ }^{180}$ Altaner, Berthold. Patrología. Ed. Espasa Calpe, Madrid, 1962, pp. 399-400.

181 Juan Pablo II. Augustinum Hipponensem, $V$.

182 ep. 41, 1.
} 